\title{
Formation of Protein Corona in vivo Affects Drug Release from Temperature-Sensitive Liposomes
}

Zahraa S. Al-Ahmady ${ }^{1 \wedge}$, Marilena Hadjidemetriou ${ }^{1 \wedge}$, James Gubbins ${ }^{1}$ and Kostas Kostarelos $^{1 *}$

${ }^{1}$ Nanomedicine Lab, Division of Pharmacy and Optometry, University of Manchester, AV Hill Building, Manchester M13 9PT, United Kingdom

\footnotetext{
${ }^{\wedge}$ These authors contributed equally to the study

* Correspondence should be addressed to: kostas.kostarelos@manchester.ac.uk
} 


\begin{abstract}
Thermally triggered drug release from temperature-sensitive liposomes (TSL) holds great promise for cancer therapy. Different types of TSL have been designed recently for heat triggered drug release inside tumor blood vessels or after accumulation into the tumor interstitium. However, justification of drug release profiles was mainly based on in vitro release data. While these methods could be good enough to give early indication about the thermal sensitivity of TSL, they are still far from being optimum. This is because these methods do not take into consideration the actual adsorption of proteins onto the surface of TSL after their in vivo administration, also known as 'protein corona' and the influence this could have on drug release. Therefore, in this study we compared thermal triggered drug release profile of two different types of doxorubicin encapsulated TSL; namely the lysolipid-containing TSL (LTSL) and traditional TSL (TTSL) after their in vivo recovery from the blood circulation of CD-1 mice. Ex vivo release profile at $42^{\circ} \mathrm{C}$ was then tested either in the presence of full plasma or after removal of unbound plasma proteins (i.e. protein corona coated TSL). Our data showed that the influence of the environment on drug release profile was very much dependent on the type of TSL. LTSL release profile was consistently characterized by ultrafast drug release independent on the conditions tested. On the contrary, TTSL release profile changed significantly. Doxorubicin release from in vivo recovered TTSL was slow and incomplete in the presence of unbound plasma proteins, whereas very rapid drug release was detected from in vivo recovered and purified protein corona-coated TTSL in the absence of unbound proteins. Using mass spectrometry and quantification of protein adsorption, we confirmed that this discrepancy is due to the changes in protein adsorption onto TTSL when heated in the presence of unbound proteins leading to reduction in drug release. In summary this study showed that the formation of the in vivo corona on TSL will have a dramatic impact on their release profile and is dependent on both their lipid composition and the protein content of the environment in which drug release is triggered.
\end{abstract}

Keywords: Temperature-sensitive liposomes, triggered release, doxorubicin, protein, hyperthermia 


\section{Highlights}

In this study we investigated in detail the effect of in vivo protein adsorption onto the surface of TSL, also known as 'protein corona' on drug release profile from TSL. Our data illustrated that the formation of the in vivo corona on TSL liposomes has a dramatic impact on their release profile. This effect is dependent on both TSL lipid composition and the protein content of the environment in which drug release is triggered. Our findings emphasize that the design of TSL for thermal triggered release cannot be predicted based on chemical composition and in vitro release studies only, but the environment of drug release should be considered. 


\section{Introduction}

Thermosensitive liposomes (TSL) represent a very promising 'smart generation' of liposomal systems for targeted and triggered drug release in response to external mild hyperthermia. Following the pioneering work of Yatvin in the late 1970s,[1] a lot of effort has been invested to explore the potential of TSL for cancer therapy. Indeed, over the past thirty years the development of TSL has been widely expanded starting from the molecular design of TSL all the way to clinical testing and determining their therapeutic aptitude [2]. Encapsulation of drug inside TSL, shields the body from the harmful effects of the drug when circulating in the blood stream. Once within the tumor, drug release from TSL can be tailored towards intravascular [3-7] or interstitial release $[4,8]$ based on the timing between TSL administration and heat application. Generally, drug release from TSL is based on passive permeability through the lipid membrane when it passes through transition temperature $(\mathrm{Tm})$. At body temperature the lipid membrane exists in solid phase only and therefore no release of hydrophilic drugs is expected. When TSL heated through their Tm, areas of the phospholipid molecules start to change from the solid (ordered) gel phase to the liquid (disordered) crystalline phase. This creates boundaries with packing defects between the two phases through which the drug permeability is enhanced. [2, 9] In addition to that, lysolipids containing TSL mediate ultrafast drug release through the formation of lysolipids stabilized long lasting pores [10]. The release of encapsulated molecules is also affected by the loading mechanism. Significant difference in the release rate of fluorescent dyes, such carboxyfluorescein (CF), was observed compared to doxorubicin (DOX) when tested under the same conditions. This difference is due to the collapse of the $\mathrm{pH}$ gradient mechanism used for DOX loading when the proton ions diffusion across the lipid membrane increases at $\operatorname{Tm}[11,12]$.

For a long time, the release profile from early types of TSL was misinterpreted as slow and incomplete under mild HT. Similarly, the relatively high Tm of this type of TSL $\left(42-45^{\circ} \mathrm{C}\right)$ suggested that high thermal dose, $1 \mathrm{~h}$ heating at temperature $>42^{\circ} \mathrm{C}$, is essential to achieve complete drug release. However, those assumptions were based on in vitro release data generated mainly in buffers and do not reflect the complexity of the physiological conditions [13-15]. It has been repeatedly reported that nanoparticles are spontaneously coated by proteins, once in contact with biofluids. Proteins adsorbed onto the surface of nanoparticles form a complex bioshell, known also as 'protein corona', the composition of which is highly affected by the physicochemical characteristics of nanoparticles. [16-19] Protein corona formation has been previously investigated for different types of liposomes, however little is known about protein corona formation on TSL. [2024] While the effect of protein corona on the cellular internalization [25], cytotoxicity [26, 27] and 
targeting capability [28-30] have been so far explored in depth, the impact of protein corona on the release profile of active molecules from nanoparticles has not been systematically studies.[31] Most of the previous studies, as will be explained in more details in the discussion, utilized in vitro drug release profile in the presence of plasma proteins to get early indication about the thermosensitive nature of TSL and the rate of drug release. However, these would not reflect the effect of actual protein adsorption under in vivo conditions.

In our previous studies, we developed a robust protocol, to investigate the in vivo protein corona formed onto clinically-used liposomes and more recently onto gold nanoparticles[32] after their recovery from the blood circulation of mice. These studies demonstrated that the molecular complexity and morphology of the in vivo protein corona cannot be adequately predicted by the in vitro plasma incubation of NPs.[23, 24] Even though the overall protein adsorption was found to be reduced by the functionalization of liposomes with PEG, it could not be fully suppressed.[23, 24] Unlike previous work, in the present study, we investigated the role of protein corona on thermal triggered release of TSL after their in vivo recovery. In this way we can better simulate the actual

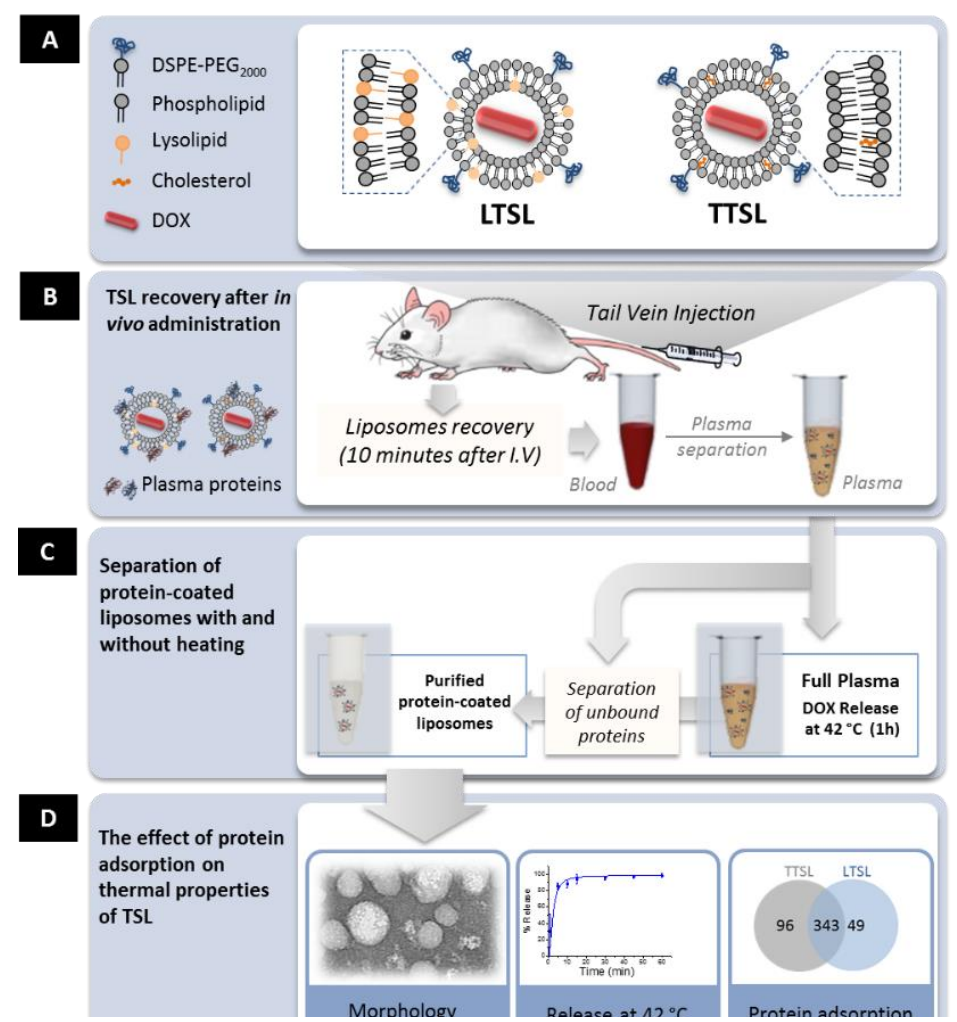

Figure 1: Schematic description of the experimental design including;(A) Composition of different temperature sensitive liposomes (TSL) used in the study, namely lysolipids TSL (LTSL) and traditional TSL (TTSL);(B) In vivo protein corona formation after intravenous injection (i.v.) into tail vein ( $n=3$ CD-1 mice/group; 3 independent experiments replicated). Ten minutes after injection TSL were recovered from the blood by cardiac puncture and the plasma was then separated from the recovered blood by centrifugation; (C) Protein-coated TSL were purified from unbound proteins with and without ex-vivo heating at $42^{\circ} \mathrm{C}$ for $1 \mathrm{~h}$; (D) Protein-coated TSL were characterized in terms of morphology, thermal sensitivity and protein adsorption profile. 
protein adsorption profile compared to simple in vitro incubation (Figure 1). In vivo protein coronas formed onto two different types of intravenously administered and doxorubicin-encapsulated TSL, namely traditional TSL (TTSL) and lysolipid-containing TSL (LTSL), were quantitatively and qualitatively characterized by mass spectrometry based proteomics. We hypothesized that TSL thermosensitivity is not only affected by the protein corona composition, but also by the environment in which the drug release is triggered. Therefore, we tested ex-vivo the release profile of doxorubicin from in vivo recovered corona-coated TSL (at $42^{\circ} \mathrm{C}$ ), in the presence of full plasma (in the presence of unbound proteins) and in buffer (i.e. protein corona coated TSL in the absence of unbound proteins).

\section{Results}

\section{Physicochemical Characterization of TSL before and after in vivo recovery}

The physicochemical characteristics of TTSL and LTSL liposome systems employed in this study are summarized in Figure 2 and Supporting table 1. Dynamic light scattering (DLS), $\zeta$-potential measurements and negative stain transmission electron microscopy (TEM) were performed prior to the in vivo administration to analyse the properties and morphology of TSL in the absence of protein adsorption. TTSL and LTSL liposome systems had a mean hydrodynamic diameter between 120-130 $\mathrm{nm}$ and a negative surface charge of 25-30 mV. All liposomal formulations displayed low polydispersity values $(<0.07)$ indicating a narrow size distribution. TEM imaging showed well-dispersed, round shaped vesicles and their size correlating that of DLS measurements (Figure 2C).

To investigate in vivo protein corona formation, TTSL and LTSL were intravenously injected and recovered from the blood circulation of CD-1 mice by cardiac puncture (Figure 1). We have previously shown that a complex protein corona is formed as early as 10 minutes post-injection.[24] Our previous time evolution data demonstrated that despite the highly dynamic protein binding kinetics, protein corona formed onto PEGylated liposomal doxorubicin does not quantitatively change overtime.[23] In addition to that, our previous pharmacokinetics studies with TTSL and LTSL showed that approximately $60-70 \%$ of the injected TSL is still in the circulation 10 minutes post-injection which allows maximum liposomes recovery.[6] For the above reasons in this study we chose to investigate in vivo protein corona formation 10 min post-injection. A protocol combining size exclusion chromatography and membrane ultrafiltration was used for the isolation of corona-coated TSL from unbound and loosely bound plasma proteins, as we have previously 
described $[23,24]$. To characterize protein coronas formed in vivo (at $37^{\circ} \mathrm{C}$ ), liposomes were immediately purified from unbound proteins after intravenous administration, while to investigate the effect of mild $\mathrm{HT}$ on the formation of protein corona, in vivo recovered plasma (containing TSL liposomes) was incubated at $42{ }^{\circ} \mathrm{C}$ for $1 \mathrm{~h}$, prior to the purification of corona-coated liposomes (Figure 1C).

The physicochemical properties of the in vivo recovered protein-coated TSL with and without prior heating at $42^{\circ} \mathrm{C}$ are shown in Figure 2. Dynamic light scattering measurements of corona-coated TSL demonstrated that their size distribution broadened (larger polydispersity
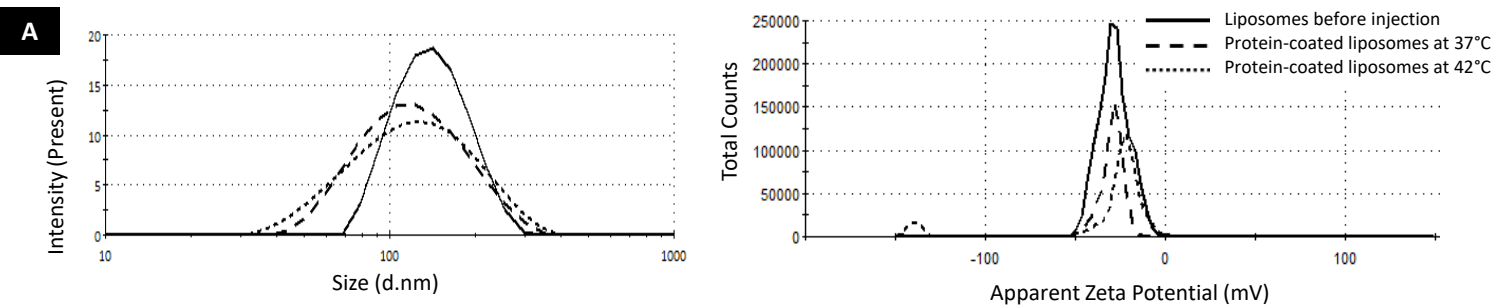

B
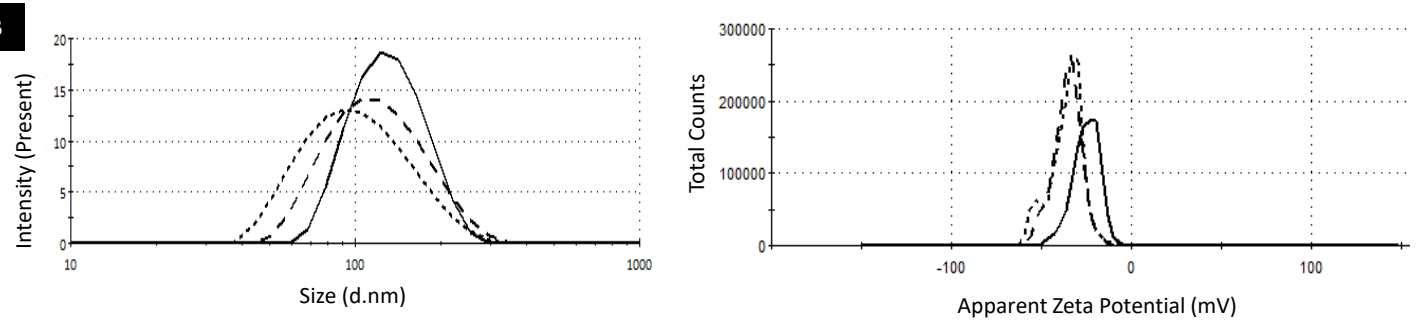

c

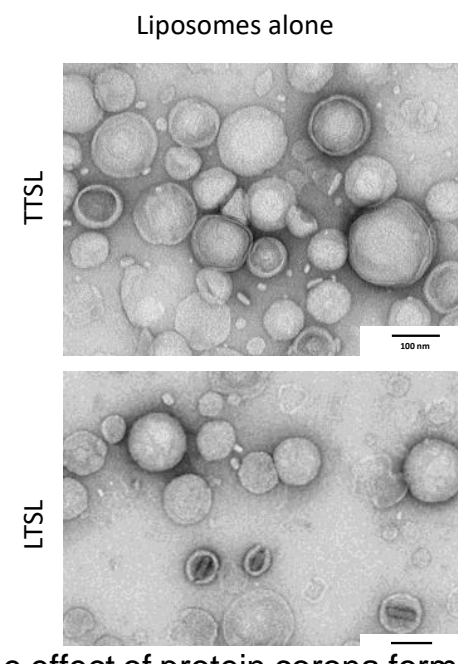

Protein-coated liposomes $\left(37^{\circ} \mathrm{C}\right) \quad$ Protein-coated liposomes $\left(\mathbf{4 2}^{\circ} \mathrm{C}\right)$
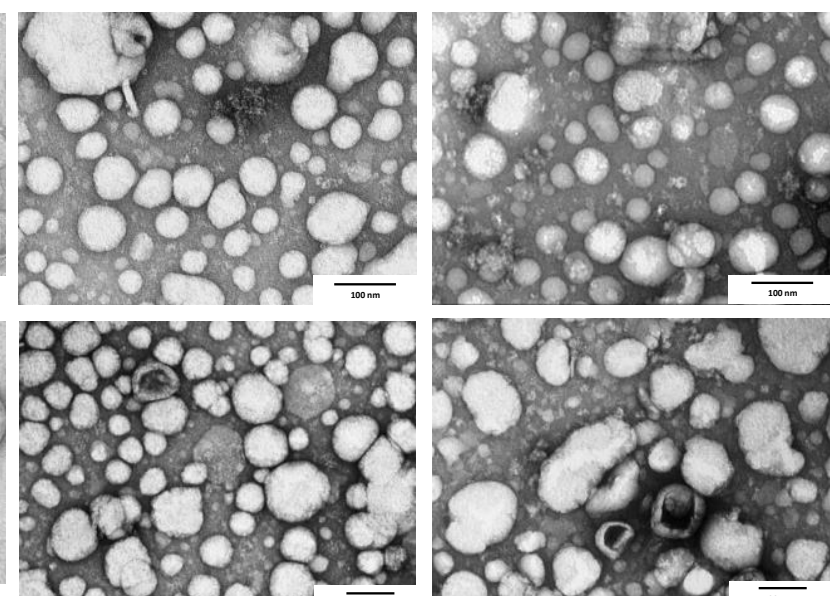

Figure 2: The effect of protein corona formation on the physicochemical characteristics of TSL. Mean diameter $(\mathrm{nm})$ and $\zeta$-potential $(\mathrm{mV})$ distributions are depicted for $(\mathbf{A})$ TTSL and $(\mathbf{B})$ LTSL liposome systems, before and after their interaction with CD-1 mouse plasma at $37^{\circ} \mathrm{C}$ and $42^{\circ} \mathrm{C}$. The graphs are representative samples from three independent experiments. (C) Negative stain transmission electron microscopy images showing the morphological and structural characterization of LTSL and TTSL systems before and after protein corona formation at $37^{\circ} \mathrm{C}$ and $42^{\circ} \mathrm{C}$. All scale bars are $100 \mathrm{~nm}$. 
index), while their surface charge remained negative, both at $37^{\circ} \mathrm{C}$ and $42^{\circ} \mathrm{C}$. In agreement with our previous studies investigating liposomal protein corona formation, we observed a bloodinduced reduction in the mean diameter of liposomes, attributed to their high elastic structure [23, 24]. This 'shrinkage effect' was much more pronounced when corona-coated liposomes were exposed to mild hyperthermia (Table S1). In terms of structural integrity and morphology, TEM images revealed well-dispersed liposomes that retained their structural integrity after in vivo recovery, while the adsorption of proteins onto their surfaces was clearly evident. Ex-vivo heating (at $42^{\circ} \mathrm{C}$ ) of the in vivo recovered TTSL did not seem to affect their shape, whereas morphological changes towards elongated vesicles were observed in the case of LTSL. The structural differences observed between TTSL and LTSL after hyperthermia could be explained by their different lipid composition and especially their unique thermal responsive components [33, 34]. LTSL are considered to be less robust compared to TTSL as no cholesterol is included in their design, in addition to the inclusion of $10 \mathrm{~mol} \%$ of lysolipids that leads to pores formation after heating at $42^{\circ} \mathrm{C}$ $[34,35]$.

Having studied TSL surface properties and morphology, TSL systems stability and thermal responsiveness were initially evaluated in vitro by studying the release of doxorubicin (DOX) from the liposomes at $37^{\circ} \mathrm{C}$ and $42^{\circ} \mathrm{C}$, respectively. In agreement with our previous findings,[6] TTSL liposomal system showed very good drug retention capability after their in vitro incubation in full plasma at $37^{\circ} \mathrm{C}(<10 \%$ DOX leakage in $24 \mathrm{~h})$. LTSL system on the other hand, exhibited short drug retention window of $<2 \mathrm{~h}$ (Figure S1A). Thermal triggered drug release from $\mathrm{TSL}\left(\right.$ at $\left.42^{\circ} \mathrm{C}\right)$ was first evaluated using traditional in vitro release methods in in buffer (Figure 3A) and full plasma (Figure 3B). As expected from the chemical design of these two liposomal systems, LTSL showed very fast and complete drug release compared to slower release profile from TTSL after incubation with plasma proteins (Figure 3B). While, similar thermal drug release profile was observed when the in vitro release was performed in buffer in the case of LTSL, very limited DOX release was observed (<10\%) for TTSL system (Figure A). The presence of plasma proteins clearly favoured the temperature sensitivity of TTSL, presumably by gaining access into the grain boundary of the lipid membrane at the transition temperature (Tm); (Figure 3B).

Because of the significant role plasma proteins play on thermal properties of some types of TSL and the fundamental differences in protein corona formation between in vitro and in vivo conditions, we studied thermal sensitivity of TSL after in vivo recovery from the blood circulation of CD1 mice. The percentage of DOX release at $42^{\circ} \mathrm{C}$ was measured ex vivo in the presence and absence of unbound proteins (Figure 3 C\&D). Interestingly, as can be observed in Figure $\mathbf{3 C}$, 
purified corona-coated TTSL (in buffer), showed very fast and complete DOX release at $42^{\circ} \mathrm{C}$.

TTSL thermal release in that case was almost identical to LTSL system. In contrast, ex vivo release at $42^{\circ} \mathrm{C}$ from TTSL, in plasma, exhibited significantly slower drug release $(p<0.05)$. LTSL thermal triggered release on the other hand was still characterized by fast drug release even when heated in the presence of unbound proteins (Figure 3D).
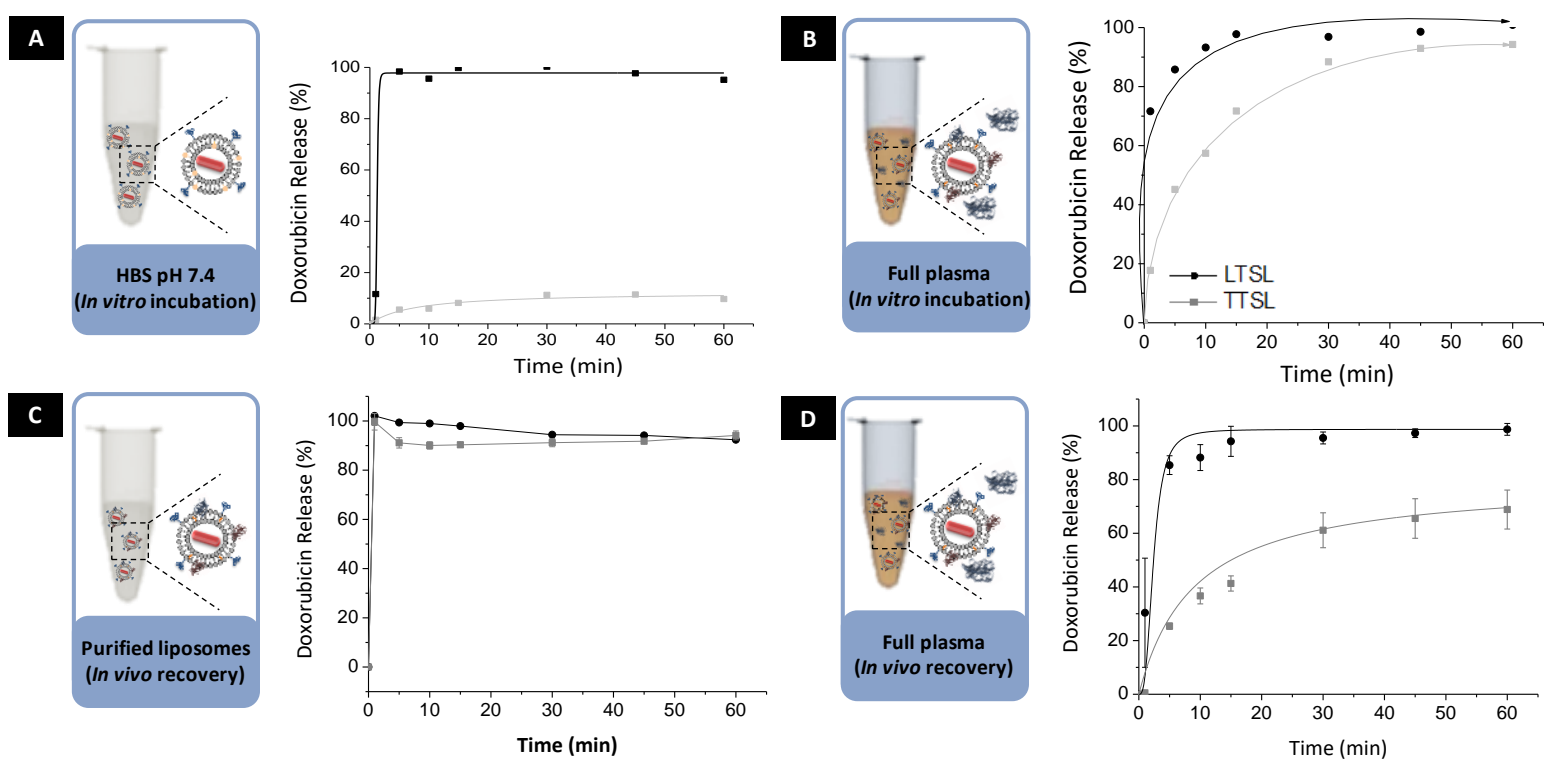

Figure 3: Temperature sensitivity of TTSL and LTSL liposome systems after $1 \mathrm{~h}$ heating in a water bath at $42^{\circ} \mathrm{C}$. The percentage of doxorubicin release from TTSL and LTSL was measured; (A) after in vitro incubation in HBS buffer $\mathrm{pH} 7.4$, (B) after in vitro incubation with full CD-1 mouse plasma, (C) from the in vivo recovered and purified liposomes (in the absence of unbound proteins) and (D) from the in vivo recovered liposomes in full plasma (before purification of unbound proteins). Statistical analysis of DOX release from TTSL from in vivo recovery in the presence and absence of unbound proteins using two-tailed unpaired student $t$-test revealed significant differences $(p$ values $<0.05)$ at all time points tested.

In order to understand the differences in the release profiles observed under the different conditions tested, we quantitatively and qualitatively characterized the in vivo protein corona formed onto the two different types of TSL. The amount of protein adsorbed was quantified by calculating the protein binding ability $(\mathrm{Pb})$, defined as the amount of proteins associated with each $\mu \mathrm{mol}$ of lipid. Interestingly, we observed that the in vivo recovered LTSL adsorbed higher amount of protein than TTSL (Figure 4A). In fact, compared to our previous studies [23, 24], LTSL adsorb almost three times more proteins than Doxil-like non-temperature sensitive PEGylated liposome system [23, 24]. This observation can be due to the difference in the fluidity of the phospholipid bilayers that can greatly influence the total amount of protein adsorbed. 


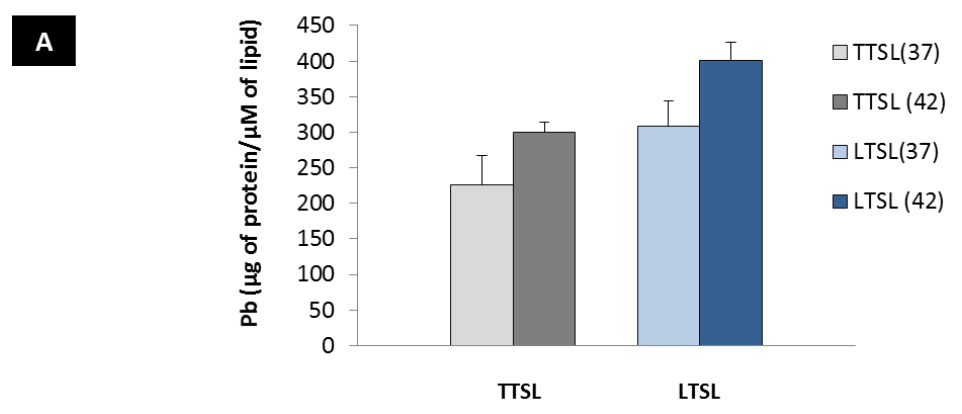

Bi

The effect of liposomal formulation

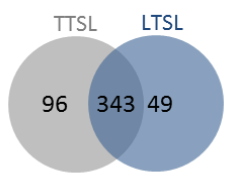

$\left(37^{\circ} \mathrm{C}\right)$

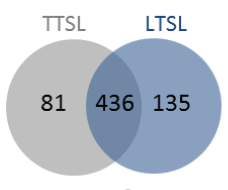

$\left(42^{\circ} \mathrm{C}\right)$
Bii

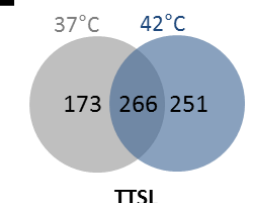

TISL

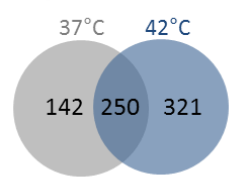

LTSL

\section{c}

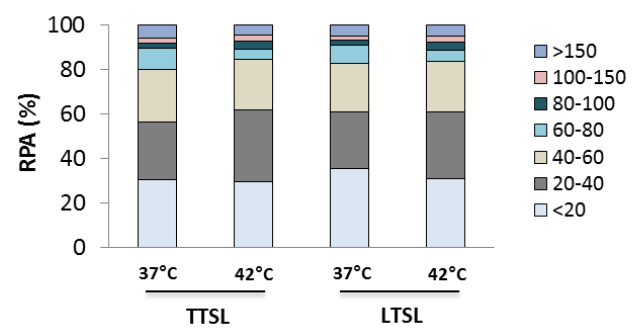

Figure 4: Comparison of protein adsorption profiles onto TTSL and LTSL formed at $37^{\circ} \mathrm{C}$ and $42^{\circ} \mathrm{C}$. (A) Comparison of the amount of proteins adsorbed onto TTSL and LTSL liposome systems. Pb values ( $\mu \mathrm{g}$ of protein $/ \mu \mathrm{M}$ lipid) represent the average and standard error from three independent experiments, each using three mice per liposome system; (Bi) Venn diagrams report the number of unique proteins identified in the $37^{\circ} \mathrm{C}$ and $42^{\circ} \mathrm{C}$ formed coronas on the two liposomal formulations tested and their respective overlap; (Bii) Venn diagrams illustrate the effect of temperature protein corona formation for TTSL and LTSL; (C) Classification of the corona proteins identified according to their molecular mass.

In addition, protein adsorption profile after heating at $42^{\circ} \mathrm{C}$ revealed a pronounced increase in the total amount of protein adsorbed for both, TTSL and LTSL (Figure 4A). The increased amount of adsorbed proteins in the case of TTSL heated ex-vivo at $42^{\circ} \mathrm{C}$ in the presence of free plasma proteins is most likely due to the increase in the bilayer fluidity. This change from the gelphase into the liquid crystalline phase could facilitate the incorporation of more proteins into the phospholipid bilayers. These data explain the highly variable release profile observed from TTSL in the different conditions tested. TTSL liposomes released $<10 \%$ of encapsulated DOX when heated in buffer (Figure 3A). This is expected from the chemical composition of TTSL. The rigid nature of TTSL due to the presence of cholesterol and HSPC lipids increases Tm to $44^{\circ} \mathrm{C}$. Therefore, when heated at $42^{\circ} \mathrm{C}$ very minimum release detected, hence most of the lipid molecules are in a highly ordered state when not in interaction with plasma proteins. In comparison, complete and ultrafast 
release was observed from in vivo recovered protein-coated TTSL heated in buffer shown in Figure $3 \mathrm{C}$, which indicates that the interaction of plasma proteins with the lipid membrane is critical to facilitate drug release from the lipid bilayer during heating. It is important to stress here that the conditions tested in this case (Figure $\mathbf{3 C}$ ) are artificial lab conditions and may not directly reflect what can happen in vivo. On the other hand, heating TTSL in full plasma both in vitro and after in vivo recovery showed slow and incomplete release profile (Figure 3B\&D) which indicates that the increased adsorption of free protein in solution on TTSL surface during heating at $42^{\circ} \mathrm{C}$ can act as a barrier to release. The release profile after heating in full plasma in vitro (Figure 3B) was slightly faster than that detected from in vivo recovery (Figure 3D). The differences in structural configuration and composition of in vitro and in vivo formed protein coronas, as we reported before [24], might explain such variability in the release profile.

The amount of adsorbed proteins on LTSL was also found to increase after heating at $42^{\circ} \mathrm{C}$ in full plasma. Despite this increase, DOX release profile from LTSL did not significantly change in the presence and absence of unbound proteins (Figure 3C\&D). Complete drug release was observed from LTSL under both heating conditions tested, however, a slightly slower release was seen in the first 5 minutes when heated in the presence of unbound proteins. Based on these results, it seems that LTSL thermal release mechanism which depends on the long lasting pores formation by the lysolipids components is possibly still retained after 10 minutes circulation in vivo. This effect has been investigated in details by Banno et al [36], showing that the retention of lysolipids in LTSL is compromised. A rapid loss of lysolipid molecules from LTSL was observed within the first 10 minutes (from $9.6 \%$ to $3.6 \%$ ) and this loss continued over time. However, the study showed that the thermosensitvity of LTSL was still retained despite such loss. In agreement with our release data, Banno et al observed $>80 \%$ DOX release from LTSL recovered 10 minutes post-injection despite the rapid loss of lysolipid molecules. Therefore, this makes LTSL liposome system ideal for intravascular drug release (if heated shortly after injection), where heating occurs in excess of free plasma protein, compared to TTSL liposome system.

Proteins associated with TTSL and LTSL liposome systems at $37^{\circ} \mathrm{C}$ and $42^{\circ} \mathrm{C}$ were separated by SDS-PAGE and visualized with EZ Blue staining (Figure S2). In agreement with protein quantification results, LTSL were found to adsorb the highest amount of proteins which further increased at $42^{\circ} \mathrm{C}$.

A comprehensive identification of proteins associated with $\mathrm{TSL}$ at $37^{\circ} \mathrm{C}$ and $42^{\circ} \mathrm{C}$ was performed by mass spectrometry. The Venn diagrams in Figure 4Bi illustrate the number of common and unique proteins adsorbed onto TTSL and LTSL at $37^{\circ} \mathrm{C}$ and $42^{\circ} \mathrm{C}$. The majority of 
proteins identified were common between TTSL and LTSL both at $37^{\circ} \mathrm{C}(\mathrm{n}=343)$ and at $42^{\circ} \mathrm{C}(\mathrm{n}=$ 436). However, the unique proteins identified (at both 37 and $42^{\circ} \mathrm{C}$ ) demonstrated that the difference in liposomal composition between TTSL and LTSL shapes protein corona formation, as previously shown by others [37]. Due to the tendency of lysolipid loss from LTSL, different protein adsorption profile may change overtime and would certainly worth more investigation. The temperature was also found to greatly influence protein adsorption profiles (Figure 4Bii). Mahmoudi et al. have previously investigated the effect of temperature on protein corona formation. The in vitro incubation of superparamagnetic nanoparticles with protein solutions at different temperatures, ranging from $5^{\circ} \mathrm{C}$ to $45^{\circ} \mathrm{C}$ resulted in different degree of protein coverage and different corona composition.[38] In our study, hyperthermia was not only found to increase the total amount of protein adsorbed onto the surface of liposomes but also modified the composition of protein corona. The ex vivo heating of TTSL and LTSL at $42^{\circ} \mathrm{C}$ was found to increase the complexity of protein corona, especially in the case of LTSL, where 321 unique proteins were identified. Our results also demonstrate that hyperthermia results in the replacement of some proteins (initially interacted with liposomes at $37^{\circ} \mathrm{C}$ ) by others. This is well illustrated by the 173 and 142 proteins, found on the surface of TTSL and LTSL respectively, only at $37^{\circ} \mathrm{C}$.

We have also classified the protein adsorption profile on TTSL and LTSL liposome systems based on the molecular weight of the proteins adsorbed. As illustrated in Figure 4C, the majority of the bound proteins $(>85 \%)$ are of low molecular weight $(\mathrm{MW}<80)$. This was in strong agreement with previous observations by us and others $[23,26]$, that the protein adsorption tendency under dynamic conditions is towards low molecular weight. Very little fluctuation in the contribution of each protein group (classified based on $\mathrm{MW}$ ) on the corona composition was observed between the two liposomes tested at $37^{\circ} \mathrm{C}$ and $42^{\circ} \mathrm{C}$. This indicates that the formation of long lasting pores after LTSL heating at $42^{\circ} \mathrm{C}$ [34] did not further enhance low molecular weight protein adsorption. To better understand the protein corona formation onto TSL, we determined the relative protein abundance (RPA) of identified proteins. Figure 5 summarizes the 20 most abundant proteins adsorbed onto in vivo recovered TTSL and LTSL before and after ex vivo heating. Apolipoproteins and immunoglobulins were the most abundant classes of corona proteins present in both conditions. RPA values demonstrated that for the two types of TSL tested the ranking of the most abundant proteins changed after ex vivo heating. For example, the RPA of Apolipoprotein C-III has dramatically decreased on both TTSL and LTSL after heating. Interestingly, albumin that is usually used as model protein to simulate the effect of protein adsorption on the release profile [39] was not identified in the top 20 proteins, both at $37^{\circ} \mathrm{C}$ and $42^{\circ} \mathrm{C}$. This indicates the specificity of the 
interaction of TSL with plasma proteins, as our previous findings demonstrated that serum albumin is indeed in the top 20 proteins adsorbed onto in vivo recovered Doxil-like non-temperature sensitive PEGylated liposome system [23, 24]. This also implies that the most abundant proteins in the plasma are not necessarily the most abundant corona proteins.[23, 24] 


\section{Discussion}

\begin{tabular}{|c|c|c|c|}
\hline \multicolumn{4}{|c|}{$37^{\circ} \mathrm{C}$} \\
\hline TTSL & RPA & LTSL & RPA \\
\hline Apolipoprotein C-III & $5.64 \pm 1.09$ & Apolipoprotein C-III & $6.38 \pm 0.82$ \\
\hline Apoe protein & $4.93 \pm 0.46$ & Beta-globin, A8DUKo (+2) & $5.72 \pm 0.41$ \\
\hline Beta-globin, A8DUK4 & $3.64 \pm 1.03$ & Apoe protein & $4.63 \pm 0.41$ \\
\hline Beta-globin, A8DUKo (+2) & $3.46 \pm 1.13$ & Beta-globin, A8DUK4 & $4.03 \pm 2.05$ \\
\hline Beta-globin OS=Mus musculus castaneus & $1.96 \pm 1.00$ & Beta-2-globin (fragment) & $3.35 \pm 0.10$ \\
\hline Beta-2-globin (fragment) & $1.95 \pm 0.47$ & Beta-globin OS=Mus musculus castaneus & $2.60 \pm 1.30$ \\
\hline Alpha-2-macroglobulin & $1.74 \pm 0.29$ & Alpha-globin 1, Q91VB8 (+2) & $2.54 \pm 0.22$ \\
\hline Alpha-globin 1, Q91VB8 (+2) & $1.56 \pm 0.32$ & Alpha-globin, A8DUV1 & $2.51 \pm 0.10$ \\
\hline Alpha-globin, A8DUV1 & $1.39 \pm 0.17$ & Apolipoprotein E & $1.68 \pm 1.68$ \\
\hline Ig mu chain $\mathrm{C}$ region & $1.19 \pm 0.13$ & Ig mu chain $\mathrm{C}$ region & $1.46 \pm 0.29$ \\
\hline Apolipoprotein A-I & $1.10 \pm 0.19$ & Alpha-2-macroglobulin & $1.41 \pm 0.33$ \\
\hline Apolipoprotein A-IV & $1.05 \pm 0.05$ & Protein Ighv7-1 & $1.04 \pm 0.23$ \\
\hline Protein Ighv7-1 & $0.93 \pm 0.13$ & Apolipoprotein A-I & $1.02 \pm 0.14$ \\
\hline Protein disulfide-isomerase & $0.91 \pm 0.07$ & Apolipoprotein A-IV & $0.96 \pm 0.17$ \\
\hline Actin, cytoplasmic 1 & $0.90 \pm 0.08$ & $\mathrm{H}-2$ class I histocompatibility antigen, Q10 alpha chain & $0.93 \pm 0.04$ \\
\hline $78 \mathrm{kDa}$ glucose-regulated protein & $0.89 \pm 0.09$ & Apolipoprotein C-IV & $0.87 \pm 0.06$ \\
\hline Corticosteroid 11-beta-dehydrogenase isozyme 1 & $0.87 \pm 0.12$ & Actin, cytoplasmic 1 & $0.85 \pm 0.10$ \\
\hline Apolipoprotein B-100 & $0.84 \pm 0.08$ & Apolipoprotein B-100 & $0.80 \pm 0.03$ \\
\hline Membrane-associated progesterone receptor component 1 & $0.81 \pm 0.10$ & Corticosteroid 11-beta-dehydrogenase isozyme 1 & $0.79 \pm 0.04$ \\
\hline
\end{tabular}

\begin{tabular}{|c|c|c|c|}
\hline \multicolumn{4}{|c|}{$42^{\circ} \mathrm{C}$} \\
\hline TTSL & RPA & LTSL & RPA \\
\hline Beta-globin, A8DUKO (+2) & $5.48 \pm 1.81$ & Beta-globin, A8DUKO (+2) & $4.47 \pm 0.54$ \\
\hline Beta-globin, A8DUK4 & $4.62 \pm 3.04$ & Beta-globin, A8DUK4 & $4.22 \pm 0.65$ \\
\hline Apoe protein & $3.84 \pm 0.22$ & Apolipoprotein C-III & $2.81 \pm 0.90$ \\
\hline Beta-2-globin (fragment) & $3.21 \pm 0.53$ & Apoe protein & $2.76 \pm 0.57$ \\
\hline Alpha-globin 1, Q91VB8 (+2) & $2.79 \pm 0.76$ & Alpha-globin 1, Q91VB8 (+2) & $2.69 \pm 0.18$ \\
\hline Alpha-globin, A8DUV1 & $2.36 \pm 0.80$ & Beta-2-globin (fragment) & $2.37 \pm 0.24$ \\
\hline Mannose-binding protein C & $1.44 \pm 0.10$ & Mannose-binding protein C & $1.48 \pm 0.31$ \\
\hline Argininosuccinate synthase & $1.36 \pm 0.19$ & Argininosuccinate synthase & $1.42 \pm 0.18$ \\
\hline Apolipoprotein C-III & $1.30 \pm 0.65$ & Alpha-globin, A8DUV1 & $1.42 \pm 0.72$ \\
\hline Apolipoprotein E & $1.21 \pm 1.21$ & Glyceraldehyde-3-phosphate dehydrogenase & $1.31 \pm 0.16$ \\
\hline Alpha-enolase & $1.13 \pm 0.13$ & Alpha-2-macroglobulin & $1.28 \pm 0.27$ \\
\hline Estradiol 17 beta-dehydrogenase 5 & $1.12 \pm 0.07$ & Alpha-enolase & $1.00 \pm 0.09$ \\
\hline Glyceraldehyde-3-phosphate dehydrogenase & $1.10 \pm 0.12$ & Estradiol 17 beta-dehydrogenase 5 & $0.93 \pm 0.10$ \\
\hline Alpha-2-macroglobulin & $1.05 \pm 0.02$ & Beta-globin OS=Mus musculus castaneus & $0.93 \pm 0.93$ \\
\hline Beta-globin OS=Mus musculus castaneus & $0.99 \pm 0.99$ & Apolipoprotein A-I & $0.90 \pm 0.26$ \\
\hline Vitronectin & $0.89 \pm 0.16$ & Ig mu chain $C$ region & $0.86 \pm 0.24$ \\
\hline Ig mu chain C region & $0.85 \pm 0.19$ & Protein Ighv7-1 & $0.84 \pm 0.19$ \\
\hline Antithrombin-III & $0.85 \pm 0.07$ & Alpha-2-HS-glycoprotein & $0.83 \pm 0.07$ \\
\hline Apolipoprotein A-I & $0.79 \pm 0.15$ & Antithrombin-III & $0.82 \pm 0.11$ \\
\hline Alpha-2-HS-glycoprotein & $0.74 \pm 0.21$ & Clusterin & $0.72 \pm 0.04$ \\
\hline
\end{tabular}

Figure 5: Most-abundant proteins (top-20) identified adsorbed onto TTSL and LTSL systems after protein corona formation at (A) $37^{\circ} \mathrm{C}$ and (B) $42^{\circ} \mathrm{C}$ measured by LCMS/MS. Relative protein abundance (RPA) values represent the average and standard error from three independent experiments, each using 3-4 mice.

Thermal triggered drug release from TSL, represents a very promising and rapidly evolving area in particular for cancer therapy [2]. Among the different triggering modality, mild hyperthermia, has provided to be one of the most promising and well controlled triggering modalities and has 
already progressed towards clinical evaluation [40-42]. The success of this smart delivery approach depends on achieving the desirable balance between minimising drug leakage at body temperature and maximizing drug release in the heated tumour [8]. Based on that, in vitro testing of drug release rate at body temperature and mild hyperthermia range $\left(41-43^{\circ} \mathrm{C}\right)$, has always been considered a prerequisite for early prediction of the therapeutic effectiveness of TSL [5, 6, 43-45]. However, the weakness of these traditional techniques is that the performance of TSL in vitro cannot directly predict their behaviour under the complex in vivo conditions. Koning and co-workers have depicted recently the different factors that can influence the performance of TSL with the aim to get more understanding about the extent that in vitro testing can be translated into in vivo therapeutic effect. These factors include; the TSL blood kinetics, the timing between injection and $\mathrm{HT}$, duration of HT and the tumour vascularisation [46].

One of the most important and instant factor is the change in surface properties of TSL once in the blood stream as a result of plasma protein adsorption. It is now well accepted that TSL behaviour is highly influenced by blood components in particular plasma proteins to variable degrees depending on the lipid composition. [2, 6, 14, 33, 39]. PEGylation could increase blood circulation time and improve thermal properties of TSL, but was shown not to be able to prevent the interaction with plasma proteins [33, 39]. Hossann et al has recently attempted to identify the effect of individual plasma components that essentially affect the integrity and thermal sensitivity of TSL. In that particular study, the rate of drug release from different types of TSL was tested in the presence of albumin, immunoglobulin and lipoprotein since they represent the major protein components in human blood. The conclusion of that study was that individual serum proteins cannot predict the complex composition of full plasma, therefore, the use of plasma or serum were considered inevitable for evaluation of TSL stability and thermal sensitivity [39]. However, the effect of serum on the release profile can vary considerably with the origin of the serum used, its concentration and the duration of exposure. This can explain the discrepancy in the release data reported from different TSL systems [14, 47]. The effect of plasma components on the thermal sensitivity of TSL can also justify the increase in therapeutic activity observed in a number of preclinical studies over a wide range of tumor models despite being considered of having slow and incomplete drug release using mild heating conditions $\left(42^{\circ} \mathrm{C}\right)$ in vitro [48]. This effect has been studied in details recently by Lokerse et al, where they compared four different types of TSL composed of DPPC:DSPC:DSPE-PEG 2000 but with different proportions of DPPC:DSPC lipids. In vitro release data after $1 \mathrm{~h}$ heating at $42^{\circ} \mathrm{C}$ revealed that drug release rate decrease with increasing DSPC lipid mol\% and indeed cryo-TEM images of liposomes at DPPC:DSPC 50:50mol\% confirmed that most of those liposomes were filled with DOX crystals which verify the slow and 
incomplete release profile. Those differences in release profile were less apparent in vivo, using intravital microscopy. Moreover, a burst effect was observed which was unexpected based on in vitro testing which again confirm the limitation of in vitro testing to predict therapeutic effectiveness [46].

Similar findings were reported before by Li et al using real-time imaging. Efficient intravascular DOX release after heating at $42^{\circ} \mathrm{C}$ was observed followed by rapid uptake of DOX by endothelial cells and tumor cells. This resulted in high and homogeneous DOX penetration into tumor cells and improved tumor growth control [11]. Li observations are in a good agreement with Manzoor et al observations showing rapid intravascular release from LTSL followed by extravasation into tumour tissue [3].

Similarly, biomolecular adsorption can influence the drug retention and in vivo behaviour of other types of nanocarriers. Peng et al has illustrated that pre-exposure of polymeric nanocarriers (loaded with coumarin-6) to bovine serum albumin reduce the drug release rate and has significant impact on in vivo behaviour (prolonged blood circulation time and changed organs distribution profile) [49]. Protein corona can also reduce burst release effect observed with protein conjugated nanocarrier (e.g. Abraxane) and surface-loaded nanocarrier (e.g. iron oxide nanoparticles) [50]. The observed decrease in drug release in those studies became more evident in the presence of unbound proteins, presumably because this will be associated with additional shielding effect [50]. Although those studies concerned with drug release at body temperature, it agrees with our findings that heat triggered drug release from TTSL was slow and incomplete when tested in the presence of unbound plasma proteins.

In addition to the effect of protein corona on drug release properties, recent efforts have illustrated that protein corona layering around nanoparticles can act as a reservoir with high payload capacity for therapeutic molecules such as anticancer drugs or genetic materials [51, 52]. The release of protein corona loaded drugs can be controlled in different ways utilising the properties of the core NP. An interesting example on that is using thermal triggered release of DOX incorporated into protein corona layer around gold nanorods (GNR). Upon exposure to external laser, incorporated DOX was released, possibility due to the restructuring process of protein corona as a result of protein denaturation in the proximity of GNR [52].

Our findings illustrated that the interaction of plasma proteins with TSL is changed after heating and this change is affected by many parameters such as the lipid composition of TSL and temperature. The variability of the protein adsorption has a clear influence on the real thermosensitivity and drug release profile observed. This observation was supported for the first time with morphological data that illustrated a very clear change in protein corona layer on TSL 
when heated in the presence of unbound proteins. Furthermore, we provided a comprehensive analysis of protein corona composition using mass spectroscopy. This illustrated that testing drug release by simple in vitro incubation is of limited value to predict the complex liposomal-protein interactions in vivo and the influences those can have on thermal triggered release. Over the past few years, several TSL systems have been designed to trigger drug release either intravenously, while still in the blood stream, or after accumulation into the tumour interstitium. As the protein species will differ significantly between the blood and tumour, the change in the release environment should be carefully considered.

To put this into a clinical context, our findings will have a great impact on the critical evaluation of TSL and iterate on the necessity to take into account the different parameters that can affect drug release. In phase III clinical trial of ThermoDOX® in combination with radiofrequency ablation (RFA) for hepatocellular carcinoma, initial data showed that the treatment did not meet the expected therapeutic efficacy compared to RFA control group. However, a recent meta-analysis of the data revealed $58 \%$ improved overall survival in a subgroup of patients who received optimized RFA for at least $45 \mathrm{~min}$. It is highly believed now that the timing and duration of heating may be the critical factors behinds ThermoDOX® clinical trial data, in addition to other peripheral hurdles that were experienced in some clinical centres [53, 54].

Taking all the above into consideration, it is evident that further systematic preclinical and clinical studies are required to offer insight into the best combination of TSL and HT protocol applied taken into consideration the chemical design of TSL and the complexity of the in vivo environment where the actual heat-triggered release will take place. 


\section{Conclusion}

Our findings illustrated that the interaction of plasma proteins with TSL is a highly variable process and affected by many parameters. The variability of the protein adsorption has a clear influence on the real thermosensitivity and drug release profile observed. This effect was very much dependent on the lipid composition of the liposomes tested and was not predictable. Using mass spectrometry and quantification of protein adsorption, we confirmed that the discrepancy in heat-triggered profile is due to the changes in protein adsorption. This illustrated that testing drug release by simple in vitro incubation is of limited value to predict the complex liposomal-protein interactions in vivo and the influences this can have on thermal triggered release. In summary, this study showed that designing TSL for thermal triggered release cannot be predicted based on chemical composition and in vitro release studies only, but the environment of drug release should be taken into account. 


\title{
Experimental
}

\begin{abstract}
Materials
Dipalmitoylphosphatidylcholine (DPPC); monostearoyl phosphatidylcholine (MSPC); hydrogenated soy phosphatidylcholine (HSPC); 1,2-distearoyl-sn-glycero-3-phosphoethanolamine- $\mathrm{N}$-[methoxy(polyethylene glycol)-2000] (ammonium salt) (DSPE-PEG2000) were purchased from Lipoid GmbH (Germany). Cholesterol, chloroform, methanol, 4-(2-Hydroxyethyl)piperazine-1-ethanesulfonic acid (HEPES), and doxorubicin hydrochloride (Dox) were purchased from Sigma (UK). All chemical substances and solvents were used without further purification.
\end{abstract}

\section{Liposome preparation and DOX encapsulation}

Two different types of TSL (TTSL and) were prepared by a thin lipid film hydration method followed by extrusion as described previously. Table S1 shows the liposomal formulation employed, the lipid composition and the molar ratios. Briefly, lipids were dissolved in chloroform:methanol mixture $(4: 1)$ in a round bottom flask and the organic solvents were then evaporated using a rotary evaporator to produce dried lipid films. Lipid films were then hydrated with ammonium sulphate $250 \mathrm{mM}(\mathrm{pH} 8.5)$ at $60^{\circ} \mathrm{C}$ and small unilamellar liposomes were produced by extrusion through $800 \mathrm{~nm}$ and $200 \mathrm{~nm}$ extrusion filters (Whatman, VWR, UK) 5 times each then 10 times through $100 \mathrm{~nm}$ filters (Whatman, VWR, UK) using a mini-Extruder (Avanti Polar Lipids, Alabaster, AL). Liposome size and surface charge were measured by using Zetasizer Nano ZS (Malvern, UK).

Doxorubicin (DOX), an anticancer drug, was loaded into TSL by the ammonium sulphate gradient method. First, external buffer was exchanged by passing the liposomes through Sepharose CL-4B gel filtration column equilibrated with HBS buffer, then incubated with DOX at $1: 20 \mathrm{DOX} /$ Lipid mass ratio at $37^{\circ} \mathrm{C}$ for LTSL ( $1.5 \mathrm{~h}$ ) or at $39^{\circ} \mathrm{C}$ for TTSL ( $5 \mathrm{~h}$ ). After incubation, liposomes were passed through PD-10 desalting columns (GE Healthcare Life Sciences) to remove any free DOX. Encapsulation efficiency (\% EE) was calculated by comparing the total fluorescence intensity of DOX post and pre gel filtration.

$\% \mathrm{EE}=\mathrm{I}(\mathrm{t})$ post column / I(t) pre column *100

Where, I(t) is the total fluorescence intensity of the liposome suspension after adding $2 \mu \mathrm{L}$ Triton $\mathrm{X}-100(10 \%$ in HBS, pH 7.4).

\section{Animal experiments}

Eight to ten week old female CD1 mice were purchased from Charles River (UK).Animal procedures were performed in compliance with the UK Home Office Code of Practice for the Housing and Care of Animals used in Scientific Procedures. Mice were housed in groups of five with free access to water and kept at temperature of $19-22{ }^{\circ} \mathrm{C}$ and relative humidity of $45-65 \%$. Before performing the procedures, animals where acclimatized to the environment for at least 7 days.

\section{TSL recovery after in vivo administration}

CD1 mice were anesthetized by inhalation of isoflurane and TSL were administered intravenously via the lateral tail vein, at a lipid dose of $0.125 \mathrm{mM} / \mathrm{g}$ body weight to achieve a final doxorubicin dose of $5 \mathrm{mg} / \mathrm{kg}$ body weight, used for preclinical studies. [5, 7, 35] 10 minutes post- injection, blood was recovered by cardiac puncture using K2EDTA coated blood collection tubes. Approximately $0.5-1 \mathrm{ml}$ of blood was recovered from each mouse. Plasma was prepared by inverting 10 times the collection tubes to ensure mixing of blood with EDTA and subsequent centrifugation for 12 minutes at $1300 \mathrm{RCF}$ at $4{ }^{\circ} \mathrm{C}$. Supernatant was collected into Protein LoBind Eppendorf Tubes and the plasma samples obtained from three mice were pooled together for a final plasma volume of $1 \mathrm{ml}$. Three experimental replicates were performed and therefore 9 mice were used in total for each time point.

\section{Serum stability and temperature sensitivity of liposomes}

In vitro release experiments were performed at $37^{\circ} \mathrm{C}$ and $42^{\circ} \mathrm{C}$ in full CD-1 mouse serum prepared by collecting $0.5-1 \mathrm{ml}$ of blood by cardiac puncture from each mouse using K2EDTA coated blood collection tubes. Blood samples were inverted 10 times to ensure proper mixing of blood with EDTA followed by subsequent centrifugation for 12 minutes at $1300 \mathrm{RCF}$ at $4{ }^{\circ} \mathrm{C}$. Release studies experiments performed with 
TSL recovered after in vivo administration were done either directly after recovery (in full plasma in the presence of free unbound plasma proteins) or after separation of protein-coated liposomes from unbound and weakly bound proteins

At different time points $10 \mu \mathrm{L}$ samples were withdrawn and further diluted to $200 \mu \mathrm{L}$ with $\mathrm{HBS}(\mathrm{pH} 7.4)$ and measured at $480 \mathrm{~nm}$ excitation wavelength and 593nm emission wavelength (slit 10/20nm) in a quartz cuvette using Cary Eclipse Fluorescence Spectrophotometer (Agilent Technologies). The intensity of the fluorescence signals was then normalized and the \% of Dox release was calculated as; Dox release $\%=[I(s)-I(0)] /[I(t)-I(0)]$, where $I(s)$ is the fluorescence intensity of individual samples at different time points, $I(0)$ is the background fluorescence intensity of liposome samples after purification and $I(\mathrm{t})$ is the fluorescence intensity of liposomes suspension after lysis with $3 \mu \mathrm{L}$ of $1 \%$ Triton X-100 in HBS followed by heating at $42^{\circ} \mathrm{C}$ for 20 minutes.

\section{Separation of protein-coated liposomes from unbound and weakly bound proteins}

TTSL and LTSL liposome systems recovered from in vivo experiments were separated form excess plasma proteins by size exclusion chromatography followed by membrane ultrafiltration, as we have previously described.[24] This process has been done wither immediately after the in vivo incubations (Protein-coated liposomes at $37^{\circ} \mathrm{C}$ ) or after $1 \mathrm{~h}$ ex-vivo heating at $42^{\circ} \mathrm{C}$ (Protein-coated liposomes at $42^{\circ} \mathrm{C}$ ). In both cases $1 \mathrm{ml}$ of plasma samples containing in vivo recovered liposomes with and without heating at $42^{\circ} \mathrm{C}$ was loaded onto a Sepharose CL-4B (SIGMA-ALDRICH) column $(15 \times 1.5 \mathrm{~cm})$ equilibrated with HBS. Chromatographic fractions 4,5 and 6 containing liposomes were then pooled together and concentrated to $500 \mu \mathrm{l}$ by centrifugation using Vivaspin 6 column (10000 MWCO, Sartorious, Fisher Scientific) at $3000 \mathrm{rpm}$. Vivaspin 500 centrifugal concentrator (1 000000 MWCO, Sartorious, Fisher Scientific) was then used at $3000 \mathrm{rpm}$, to further concentrate the samples to $100 \mu \mathrm{l}$ and to ensure separation of protein-coated liposomes from the remaining large unbound proteins. Liposomes were then washed 3 times with $100 \mu \mathrm{l} \mathrm{HBS}$ to remove weekly bound proteins.

Please note that the procedures of liposomes purification with Sepharose CL-4B and Vivaspin has no impact on liposomes size and DPI. These are routinely used procedures for DOX encapsulation (table S1).

\section{Size and zeta potential measurements using dynamic light scattering (DLS)}

After incubation of liposomes at different temperature for each condition tested, DLS measurements were performed at RT $\left(25^{\circ} \mathrm{C}\right)$. Liposome size and surface charge were measured using Zetasizer Nano ZS (Malvern, Instruments, UK). For size measurement, samples were diluted with distilled water in $1 \mathrm{ml}$ cuvettes. Zeta potential was measured in disposable Zetasizer cuvettes and sample dilution was performed with distilled water. Size and zeta potential data were taken in three and five measurements, respectively.

\section{Transmission electron microscopy (TEM)}

TSL under different conditions tested were visualized with transmission electron microscopy (FEI Tecnai 12 BioTwin) before and after their in vivo interaction with plasma proteins at $37^{\circ} \mathrm{C}$ and $42^{\circ} \mathrm{C}$. Samples were diluted to $1 \mathrm{mM}$ lipid concentration, then a drop from each liposome suspension was placed onto a Carbon Film Mesh Copper Grid (CF400-Cu, Electron Microscopy Science) and the excess suspension was removed with a filter paper. Staining was performed using aqueous uranyl acetate solution $1 \%$.

\section{Quantification of adsorbed proteins}

Proteins associated with recovered liposomes were quantified by BCA Protein assay kit. Pb values, expressed as $\mu \mathrm{g}$ of protein $/ \mu \mathrm{M}$ lipid were then calculated and represented as the average \pm standard error of three independent experiments. For the BCA assay, a 6-point standard curve was generated by serial dilutions of BSA in HBS, with the top standard at a concentration of $2 \mu \mathrm{g} / \mathrm{ml}$. BCA reagent $A$ and $B$ were mixed at a ratio of 50:1 and $200 \mu \mathrm{l}$ of the BCA mixture were dispensed into a 96-well plate, in duplicates. Then, $25 \mu \mathrm{l}$ of each standard or unknown sample were added per well. The plate was incubated for 30 minutes at $37^{\circ} \mathrm{C}$, after which the absorbance was read at $574 \mathrm{~nm}$ on a plate reader (Fluostar Omega). Protein concentrations were calculated according to the standard curve. To quantify lipid concentration, $20 \mu l$ of each samples was mixed with $1 \mathrm{ml}$ of chloroform and $500 \mu \mathrm{l}$ of Stewart assay reagent in an Eppendorf tube. The

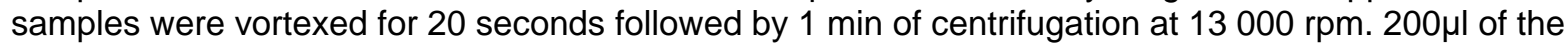


chloroform phase was transferred to a quartz cuvette. The optical density was measured using Cary 50 Bio Spectrophotometer (Agilent Technologies) at $485 \mathrm{~nm}$. Lipid concentration was calculated according to a standard curve.

\section{Mass Spectrometry}

Proteins associated with $0.05 \mu \mathrm{M}$ of in vivo recovered TSL were mixed with Protein Solving Buffer (Fisher Scientific) for a final volume of $25 \mu \mathrm{l}$ and boiled for 5 minutes at $90^{\circ} \mathrm{C}$. Samples were then loaded in $10 \%$ Precise Tris-HEPES Protein Gel (Thermo Scientific). The gel was run for 3-5 minutes 100V, in 50 times diluted Tris-HEPES SDS Buffer (Thermo Scientific). Staining was performed with EZ Blue ${ }^{\mathrm{TM}}$ Gel Staining reagent (Sigma Life Science) overnight followed by washing in distilled water for $2 \mathrm{~h}$. Bands of interest were excised from the gel and dehydrated using acetonitrile followed by vacuum centrifugation. Dried gel pieces were reduced with $10 \mathrm{mM}$ dithiothreitol and alkylated with $55 \mathrm{mM}$ iodoacetamide. Gel pieces were then washed alternately with $25 \mathrm{mM}$ ammonium bicarbonate followed by acetonitrile. This was repeated, and the gel pieces dried by vacuum centrifugation. Samples were digested with trypsin overnight at $37^{\circ} \mathrm{C}$.

Digested samples were analysed by LC-MS/MS using an UltiMate ${ }^{\circledR} 3000$ Rapid Separation LC (RSLC, Dionex Corporation, Sunnyvale, CA) coupled to Orbitrap Velos Pro (Thermo Fisher Scientific) mass spectrometer. Peptide mixtures were separated using a gradient from $92 \% \mathrm{~A}(0.1 \% \mathrm{FA}$ in water) and $8 \% \mathrm{~B}$ $\left(0.1 \% \mathrm{FA}\right.$ in acetonitrile) to $33 \% \mathrm{~B}$, in $44 \mathrm{~min}$ at $300 \mathrm{~nL} \mathrm{~min}^{-1}$, using a $250 \mathrm{~mm} \times 75 \mu \mathrm{m}$ i.d. $1.7 \mu \mathrm{M} \mathrm{BEH} \mathrm{C18}$, analytical column (Waters). Peptides were selected for fragmentation automatically by data dependant analysis. Data produced were searched using Mascot (Matrix Science UK), against the [Uniprot] database with taxonomy of [mouse] selected. Data were validated using Scaffold (Proteome Software, Portland, OR).

The Scaffold software (version 4.3.2, Proteome Software Inc.) was used to validate MS/MS based peptide and protein identifications and for relative quantification based on spectral counting. Peptide identifications were accepted if they could be established at greater than $95.0 \%$ probability by the Peptide Prophet algorithm with Scaffold delta-mass correction. Protein identifications were accepted if they could be established at greater than $99.0 \%$ probability and contained at least 2 identified peptides. Protein probabilities were assigned by the Protein Prophet algorithm. Proteins that contained similar peptides and could not be differentiated based on MS/MS analysis alone were grouped to satisfy the principles of parsimony. Semi quantitative assessment of the protein amounts was conducted using normalized spectral counting, NSCs, provided by Scaffold Software. The mean value of NSCs obtained in the three experimental replicates for each protein was normalized to the protein MW and expressed as a relative quantity by applying the following equation:

$$
\mathrm{MWNSC}_{\mathrm{k}}=\frac{(\mathrm{NSC} / \mathrm{MW})_{\mathrm{k}}}{\sum_{i=1}^{N}(\mathrm{NSC} / \mathrm{MW})_{i}} \times 100
$$

where, MWNSCk is the percentage molecular weight normalized NSC for protein $\mathrm{k}$ and MW is the molecular weight in $\mathrm{kDa}$ for protein $\mathrm{k}$. This equation takes into consideration the protein size and evaluates the contribution of each protein reflecting its relative protein abundance (RPA).

\section{Statistical Analysis}

Statistical analysis of the data was performed using Graph Pad Prism software. Two-tailed unpaired student $t$-test was used and $p$ values $<0.05$ was considered significant.

\section{Conflict of Interest}

The authors declare no competing financial interest. 


\section{Author Contributions}

Z.A. designed, planned and led the study, performed in vivo experiments, DOX encapsulation, DLS measurements, release studies, prepared figures and wrote the manuscript. M.H performed the recovery and purification of liposomes from plasma, TEM and protein corona characterization (SDS-PAGE, BCA assay and Mass Spectrometry). J.G prepared TSL formulation, DOX encapsulation and release studies. Z.A, M.H and K.K wrote and reviewed the manuscript

\section{Acknowledgments}

This research was partially funded by the Marie Curie Initial Training Network PathChooser (PITN-GA-2013-608373). The authors also wish to thank the staff in the Faculty of Life Sciences EM Facility for their assistance and the Wellcome Trust for equipment grant support to the EM Facility. In addition, Mass Spectrometry Facility staff at the University of Manchester for their assistance. 


\section{References}

[1] M.B. Yatvin, J.N. Weinstein, W.H. Dennis, R. Blumenthal, Design of liposomes for enhanced local release of drugs by hyperthermia, Science, 202 (1978) 1290-1293.

[2] Z.S. Al-Ahmady, K. Kostarelos, Chemical Components for the Design of Temperature-Responsive Vesicles as Cancer Therapeutics, Chem. Rev., 116 (2016) 3883-3918.

[3] A.A. Manzoor, L.H. Lindner, C.D. Landon, J.Y. Park, A.J. Simnick, M.R. Dreher, S. Das, G. Hanna, W. Park, A. Chilkoti, G.A. Koning, T.L. ten Hagen, D. Needham, M.W. Dewhirst, Overcoming limitations in nanoparticle drug delivery: triggered, intravascular release to improve drug penetration into tumors, Cancer Res., 72 (2012) 5566-5575. [4] Z.S. Al-Ahmady, O. Chaloin, K. Kostarelos, Monoclonal antibody-targeted, temperature-sensitive liposomes: in vivo tumor chemotherapeutics in combination with mild hyperthermia, J. Controlled Release, 196 (2014) 332-343. [5] Z.S. Al-Ahmady, W.T. Al-Jamal, J.V. Bossche, T.T. Bui, A.F. Drake, A.J. Mason, K. Kostarelos, Lipid-peptide vesicle nanoscale hybrids for triggered drug release by mild hyperthermia in vitro and in vivo, ACS Nano, 6 (2012) 9335-9346.

[6] W.T. Al-Jamal, Z.S. Al-Ahmady, K. Kostarelos, Pharmacokinetics \& tissue distribution of temperature-sensitive liposomal doxorubicin in tumor-bearing mice triggered with mild hyperthermia, Biomaterials, 33 (2012) 4608-4617. [7] G. Kong, G. Anyarambhatla, W.P. Petros, R.D. Braun, O.M. Colvin, D. Needham, M.W. Dewhirst, Efficacy of liposomes and hyperthermia in a human tumor xenograft model: importance of triggered drug release, Cancer Res., 60 (2000) 6950-6957.

[8] Z.S. Al-Ahmady, C.L. Scudamore, K. Kostarelos, Triggered doxorubicin release in solid tumors from thermosensitive liposome-peptide hybrids: Critical parameters and therapeutic efficacy, Int. J. Cancer, 137 (2015) 731743.

[9] C.D. Landon, J.-Y. Park, D. Needham, M.W. Dewhirst, Nanoscale drug delivery and hyperthermia: the materials design and preclinical and clinical testing of low temperature-sensitive liposomes used in combination with mild hyperthermia in the treatment of local cancer, Open Nanomedicine Journal, 3 (2011) 38-64.

[10] D. Needham, J.-Y. Park, A.M. Wright, J. Tong, Materials characterization of the low temperature sensitive liposome (LTSL): effects of the lipid composition (lysolipid and dspe-peg2000) on the thermal transition and release of doxorubicin, Faraday Discuss., 161 (2013) 515-534.

[11] L. Li, T.L. Ten Hagen, M. Hossann, R. Suss, G.C. van Rhoon, A.M. Eggermont, D. Haemmerich, G.A. Koning, Mild hyperthermia triggered doxorubicin release from optimized stealth thermosensitive liposomes improves intratumoral drug delivery and efficacy, J. Controlled Release, 168 (2013) 142-150.

[12] L. Li, T.L.M. ten Hagen, D. Schipper, T.M. Wijnberg, G. Van Rhoon, A.M.M. Eggermont, L.H. Lindner, G.A. Koning, Triggered content release from optimized stealth thermosensitive liposomes using mild hyperthermia, J. Controlled Release, 143 (2010) 274-279.

[13] T. Hosokawa, M. Sami, Y. Kato, E. Hayakawa, Alteration in the temperature-dependent content release property of thermosensitive liposomes in plasma, Chem. Pharm. Bull., 51 (2003) 1227-1232.

[14] M.H. Gaber, K.L. Hong, S.K. Huang, D. Papahadjopoulos, Thermosensitive sterically stabilized liposomes formulation and in-vitro studies on mechanism of doxorubicin release by bovine serum and human plasma, Pharm. Res., 12 (1995) 1407-1416.

[15] S. Unezaki, K. Maruyama, N. Takahashi, M. Koyama, T. Yuda, A. Suginaka, M. Iwatsuru, Enhanced delivery and antitumor-activity of doxorubicin using long-circulating thermosensitive liposomes containing amphipathic polyethylene-glycol in combination with local hyperthermia, Pharm. Res., 11 (1994) 1180-1185.

[16] T. Cedervall, I. Lynch, S. Lindman, T. Berggard, E. Thulin, H. Nilsson, K.A. Dawson, S. Linse, Understanding the nanoparticle-protein corona using methods to quantify exchange rates and affinities of proteins for nanoparticles, Proc Natl Acad Sci U S A, 104 (2007) 2050-2055.

[17] M. Hadjidemetriou, K. Kostarelos, Nanomedicine: Evolution of the nanoparticle corona, Nat Nanotechnol, 12 (2017) 288-290.

[18] M.P. Monopoli, A.S. Pitek, I. Lynch, K.A. Dawson, Formation and characterization of the nanoparticle-protein corona, Methods Mol Biol, 1025 (2013) 137-155.

[19] S. Tenzer, D. Docter, J. Kuharev, A. Musyanovych, V. Fetz, R. Hecht, F. Schlenk, D. Fischer, K. Kiouptsi, C. Reinhardt, K. Landfester, H. Schild, M. Maskos, S.K. Knauer, R.H. Stauber, Rapid formation of plasma protein corona critically affects nanoparticle pathophysiology, Nat. Nanotechnol., 8 (2013) 772-781.

[20] S. Palchetti, V. Colapicchioni, L. Digiacomo, G. Caracciolo, D. Pozzi, A.L. Capriotti, G. La Barbera, A. Lagana, The protein corona of circulating PEGylated liposomes, Biochim Biophys Acta, 2 (2016) 189-196.

[21] A. Chonn, S.C. Semple, P.R. Cullis, Association of blood proteins with large unilamellar liposomes in vivo. Relation to circulation lifetimes, J. Biol. Chem., 267 (1992) 18759-18765. 
[22] T.M. Allen, C. Hansen, F. Martin, C. Redemann, A. Yau-Young, Liposomes containing synthetic lipid derivatives of poly(ethylene glycol) show prolonged circulation half-lives in vivo, Biochim. Biophys. Acta, 1 (1991) 29-36.

[23] M. Hadjidemetriou, Z. Al-Ahmady, K. Kostarelos, Time-evolution of in vivo protein corona onto blood-circulating PEGylated liposomal doxorubicin (DOXIL) nanoparticles, Nanoscale, 8 (2016) 6948-6957.

[24] M. Hadjidemetriou, Z. Al-Ahmady, M. Mazza, R.F. Collins, K. Dawson, K. Kostarelos, In Vivo Biomolecule Corona around Blood-Circulating, Clinically Used and Antibody-Targeted Lipid Bilayer Nanoscale Vesicles, ACS Nano, 9 (2015) 8142-8156.

[25] S. Tenzer, D. Docter, J. Kuharev, A. Musyanovych, V. Fetz, R. Hecht, F. Schlenk, D. Fischer, K. Kiouptsi, C. Reinhardt, K. Landfester, H. Schild, M. Maskos, S.K. Knauer, R.H. Stauber, Rapid formation of plasma protein corona critically affects nanoparticle pathophysiology, Nat Nanotechnol, 8 (2013) 772-781.

[26] D. Pozzi, G. Caracciolo, L. Digiacomo, V. Colapicchioni, S. Palchetti, A.L. Capriotti, C. Cavaliere, R. Zenezini Chiozzi, A. Puglisi, A. Lagana, The biomolecular corona of nanoparticles in circulating biological media, Nanoscale, 7 (2015) 13958-13966.

[27] C. Ge, J. Du, L. Zhao, L. Wang, Y. Liu, D. Li, Y. Yang, R. Zhou, Y. Zhao, Z. Chai, C. Chen, Binding of blood proteins to carbon nanotubes reduces cytotoxicity, Proc Natl Acad Sci U S A, 108 (2011) 16968-16973.

[28] A. Salvati, A.S. Pitek, M.P. Monopoli, K. Prapainop, F.B. Bombelli, D.R. Hristov, P.M. Kelly, C. Aberg, E. Mahon, K.A. Dawson, Transferrin-functionalized nanoparticles lose their targeting capabilities when a biomolecule corona adsorbs on the surface, Nat Nanotechnol, 8 (2013) 137-143.

[29] V. Mirshafiee, M. Mahmoudi, K. Lou, J. Cheng, M.L. Kraft, Protein corona significantly reduces active targeting yield, Chem Commun 49 (2013) 2557-2559.

[30] Q. Dai, C. Walkey, W.C. Chan, Polyethylene glycol backfilling mitigates the negative impact of the protein corona on nanoparticle cell targeting, Angew Chem Int Ed Engl, 53 (2014) 5093-5096.

[31] A. Pourjavadi, Z.M. Tehrani, N. Mahmoudi, The effect of protein corona on doxorubicin release from the magnetic mesoporous silica nanoparticles with polyethylene glycol coating, Journal of Nanoparticle Research, 17 (2015).

[32] R. Garcia-Alvarez, M. Hadjidemetriou, A. Sanchez-Iglesias, L.M. Liz-Marzan, K. Kostarelos, In vivo formation of protein corona on gold nanoparticles. The effect of their size and shape, Nanoscale, 10 (2018) 1256-1264.

[33] M.H. Gaber, Effect of bovine serum on the phase transition temperature of cholesterol-containing liposomes, J. Microencapsulation, 15 (1998) 207-214.

[34] J.K. Mills, D. Needham, lysolipid incorporation in dipalmitoylphosphatidylcholine bilayer membranes enhances the ion permeability and drug release rates at the membrane phase transition, Biochim. Biophys. Acta, Biomembr., 1716 (2005) 77-96.

[35] D. Needham, G. Anyarambhatla, G. Kong, M.W. Dewhirst, A new temperature-sensitive liposome for use with mild hyperthermia: characterization and testing in a human tumor xenograft model, Cancer Res., 60 (2000) 1197-1201.

[36] B. Banno, L.M. Ickenstein, G.N. Chiu, M.B. Bally, J. Thewalt, E. Brief, E.K. Wasan, The functional roles of poly(ethylene glycol)-lipid and lysolipid in the drug retention and release from lysolipid-containing thermosensitive liposomes in vitro and in vivo, J. Pharm. Sci., 99 (2010) 2295-2308.

[37] G. Caracciolo, D. Pozzi, A.L. Capriotti, C. Cavaliere, S. Piovesana, H. Amenitsch, A. Lagana, Lipid composition: a "key factor" for the rational manipulation of the liposome-protein corona by liposome design, RSC Advances, 5 (2015) 5967-5975.

[38] M. Mahmoudi, A.M. Abdelmonem, S. Behzadi, J.H. Clement, S. Dutz, M.R. Ejtehadi, R. Hartmann, K. Kantner, U. Linne, P. Maffre, S. Metzler, M.K. Moghadam, C. Pfeiffer, M. Rezaei, P. Ruiz-Lozano, V. Serpooshan, M.A.

Shokrgozar, G.U. Nienhaus, W.J. Parak, Temperature: the "ignored" factor at the NanoBio interface, ACS Nano, 7 (2013) 6555-6562.

[39] M. Hossann, Z. Syunyaeva, R. Schmidt, A. Zengerle, H. Eibl, R.D. Issels, L.H. Lindner, Proteins and cholesterol lipid vesicles are mediators of drug release from thermosensitive liposomes, J Control Release, 162 (2012) 400-406.

[40] M.W. Dewhirst, C.D. Landon, C.L. Hofmann, P.R. Stauffer, Novel approaches to treatment of hepatocellular carcinoma and hepatic metastases using thermal ablation and thermosensitive liposomes, Surg Oncol Clin N Am, 22 (2013) 545-561.

[41] ClinicalTrials.gov, A Study of ThermoDox ${ }^{\mathrm{TM}}$ in Combination With Radiofrequency Ablation (RFA) in Primary and Metastatic Tumors of the Liver (NCT00441376), in, 2015.

[42] ClinicalTrials.gov, Phase 1/2 Study of ThermoDox With Approved Hyperthermia in Treatment of Breast Cancer Recurrence at the Chest Wall, in, 2015.

[43] M. Hossann, M. Wiggenhorn, A. Schwerdt, K. Wachholz, N. Teichert, H. Eibl, R.D. Issels, L.H. Lindner, In vitro stability and content release properties of phosphatidylglyceroglycerol containing thermosensitive liposomes, Biochim. Biophys. Acta, Biomembr., 1768 (2007) 2491-2499. 
[44] S.M. Park, M.S. Kim, S.J. Park, E.S. Park, K.S. Choi, Y.S. Kim, H.R. Kim, Novel temperature-triggered liposome with high stability: formulation, in vitro evaluation, and in vivo study combined with high-intensity focused ultrasound (HIFU), J. Controlled Release, 170 (2013) 373-379.

[45] T. Tagami, M.J. Ernsting, S.-D. Li, Optimization of a novel and improved thermosensitive liposome formulated with DPPC and a Brij surfactant using a robust in vitro system, J. Controlled Release, 154 (2011) 290-297.

[46] W.J. Lokerse, E.C. Kneepkens, T.L. Ten Hagen, A.M. Eggermont, H. Grull, G.A. Koning, In depth study on thermosensitive liposomes: Optimizing formulations for tumor specific therapy and in vitro to in vivo relations, Biomaterials, 82 (2016) 138-150.

[47] M. de Smet, S. Langereis, S. van den Bosch, H. Gruell, Temperature-sensitive liposomes for doxorubicin delivery under MRI guidance, J. Controlled Release, 143 (2010) 120-127.

[48] G. Kong, M.W. Dewhirst, Hyperthermia and liposomes, Int. J. Hyperthermia, 15 (1999) 345-370.

[49] Q. Peng, X.Q. Wei, Q. Yang, S. Zhang, T. Zhang, X.R. Shao, X.X. Cai, Z.R. Zhang, Y.F. Lin, Enhanced biostability of nanoparticle-based drug delivery systems by albumin corona, Nanomedicine, 10 (2015) 205-214.

[50] S. Behzadi, V. Serpooshan, R. Sakhtianchi, B. Muller, K. Landfester, D. Crespy, M. Mahmoudi, Protein corona change the drug release profile of nanocarriers: the "overlooked" factor at the nanobio interface, Colloids Surf., B, 123 (2014) 143-149.

[51] A. Cifuentes-Rius, H. de Puig, J.C. Kah, S. Borros, K. Hamad-Schifferli, Optimizing the properties of the protein corona surrounding nanoparticles for tuning payload release, ACS Nano, 7 (2013) 10066-10074.

[52] J.C. Kah, J. Chen, A. Zubieta, K. Hamad-Schifferli, Exploiting the protein corona around gold nanorods for loading and triggered release, ACS Nano, 6 (2012) 6730-6740.

[53] Celsion.com, Celsion Corporation Announces Updated Overall Survival Data from HEAT Study of ThermoDox® in Primary Liver Cancer, in, 2015.

[54] D. Needham, Chapter 12 - Reverse Engineering of the Low Temperature-Sensitive Liposome (LTSL) for Treating Cancer, in: K. Park (Ed.) Biomaterials for Cancer Therapeutics, Woodhead Publishing, 2013, pp. 270-353e. 


\section{SUPPORTING INFORMATION}

\section{Formation of Protein Corona in vivo Affects Drug Release from Temperature-Sensitive Liposomes}

Zahraa S. Al-Ahmady ${ }^{1 \wedge}$, Marilena Hadjidemetriou ${ }^{1 \wedge}$, James Gubbins ${ }^{1}$ and Kostas Kostarelos $^{1 *}$

${ }^{1}$ Nanomedicine Lab, Division of Pharmacy and Optometry, University of Manchester, AV Hill Building, Manchester M13 9PT, United Kingdom 
Supporting TableS1: Physicochemical Characterization of LTSL and TTSL used in this study: Hydrodynamic Diameter, Polydispersity Index, Zeta-Potential

\begin{tabular}{|c|c|c|c|c|}
\hline $\begin{array}{l}\text { TSL system / } \\
\text { lipid molar ratios }\end{array}$ & & $\begin{array}{l}\text { Hydrodynamic } \\
\text { diameter(nm) }\end{array}$ & $\begin{array}{l}\text { Polydispersity } \\
\text { Index, PDI }\end{array}$ & $\begin{array}{l}\text { Zeta Potential, } \\
\zeta(\mathrm{mV})\end{array}$ \\
\hline \multirow{4}{*}{$\begin{array}{l}\text { TTSL } \\
\text { DPPC:HSPC:CHOL:DSPE- } \\
\text { PEG }_{2000}(54: 27: 16: 3)\end{array}$} & \multirow{4}{*}{$\begin{array}{l}\text { Liposomes without } \\
\text { DOX } \\
\text { Liposomes DOX } \\
\text { before injected } \\
\text { Protein-coated } \\
\text { liposomes at } 37^{\circ} \mathrm{C} \\
\text { Protein-coated } \\
\text { liposomes at } 42^{\circ} \mathrm{C}\end{array}$} & $127.9 \pm 1.6$ & $0.05 \pm 0.021$ & \\
\hline & & $132 \pm 1.8$ & $0.07 \pm 0.009$ & $-29.7 \pm 1.01$ \\
\hline & & $112 \pm 03$ & $0.17 \pm 0.010$ & $-33.3 \pm 2.40$ \\
\hline & & $102 \pm 04$ & $0.16 \pm 0.010$ & $-34.1 \pm 1.50$ \\
\hline \multirow{4}{*}{$\begin{array}{l}\text { LTSL } \\
\text { DPPC:MSPC:DSPE- } \\
\text { PEG }_{2000}(90: 10: 4)\end{array}$} & \multirow{4}{*}{$\begin{array}{l}\text { Liposomes without } \\
\text { DOX } \\
\text { Liposomes DOX } \\
\text { before injected } \\
\text { Protein-coated } \\
\text { liposomes at } 37 \\
\text { Protein-coated } \\
\text { liposomes at } 42^{\circ} \mathrm{C}\end{array}$} & $124.5 \pm 1.77$ & $0.075 \pm 0.014$ & \\
\hline & & $122 \pm 1.2$ & $0.06 \pm 0.005$ & $-24.6 \pm 0.67$ \\
\hline & & $108 \pm 03$ & $0.15 \pm 0.010$ & $-35.6 \pm 2.30$ \\
\hline & & $95.9 \pm 2.98$ & $0.19 \pm 0.020$ & $-36.1 \pm 2.01$ \\
\hline
\end{tabular}




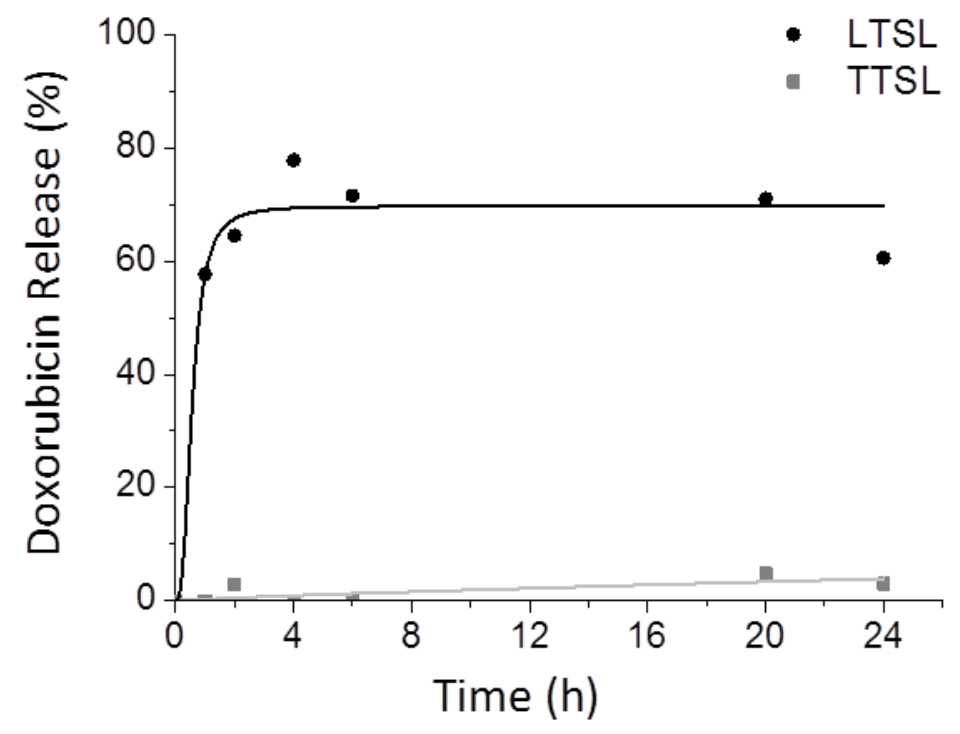

Supporting Figure S1: Serum stability and temperature sensitivity of TTSL and LTSL liposome systems before injection. The percentage of doxorubicin release from TTSL and LTSL liposomes was measured before injection in full CD-1 mouse plasma at $37^{\circ} \mathrm{C}$ over $24 \mathrm{~h}$. 


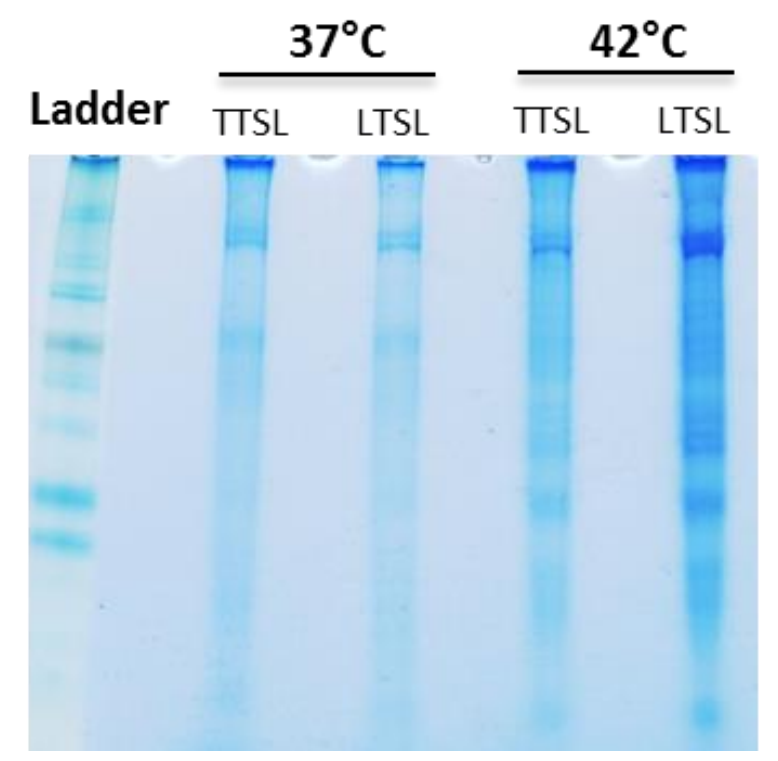

Supporting Figure S2: EZ-Blue stained SDS-PAGE gel comparing the protein adsorption profiles onto TTSL and LTSL formed at $37^{\circ} \mathrm{C}$ and $42^{\circ} \mathrm{C}$. SDS-PAGE data showed qualitatively higher protein adsorption onto LTSL liposome system at $42^{\circ} \mathrm{C}$ compared to LTSL liposomes at $37^{\circ} \mathrm{C}$ and TTSL liposomes at both conditions tested. 